Reprod. Nutr. Dévelop., 1984, 24 (5A), 633-654.

\title{
Évolution des cellules germinales femelles au cours de la prophase méiotique chez le rat : critères de reconnaissances cytoplasmique et nucléaire des différents stades en histologie fine
}

\author{
Jacqueline BÉZARD, P. MAULÉON
}

Station de Physiologie de la Reproduction, I.N.R.A., Nouzilly, 37380 Monnaie, France.

Summary. Evolution of female germ cells during the meiotic prophase in the rat : criteria for cytoplasmic and nuclear identification of the different stages by thin histology.

The different stages of meiotic prophase in germ cells of the rat ovary were studied cytologically at definite times when there was a dominant nuclear stage.

Each stage was identified in $1 \mu$ sections. The usual references for the definition of meiotic nuclear stages according to chromosomal structures were used and have been described in more detail. It has also been shown that cytological observations such as the organization and distribution of cytoplasmic organelles (mitochondria, Golgi apparatus) equally contributes to the identification of the stages of meiotic prophase.

\section{Introduction.}

De nombreuses descriptions des différents stades de la méiose ont été faites d'abord avec des techniques histologiques classiques merveilleusement précises mais longues, à cause des techniques de différenciation très artistiques (Winiwarter, 1901 et Winiwarter et Sainmont, 1909). Ces techniques ont évolué vers des méthodes rapides (hématoxyline éosine ou Feulgen) donnant des images nucléaires confuses surtout pour les premiers stades de la prophase méiotique. Or, lorsque l'on aborde l'étude des mécanismes d'induction, ce sont pourtant ces premiers stades qu'il convient de connaître avec précision. Les techniques cytologiques $n$ 'ont pas ces défauts mais ne donnent aucune information sur les relations cellules germinales - cellules somatiques que l'on estime déterminantes lors du déroulement de l'ovogenèse.

Les deux méthodes précédentes n'apportent pas d'information au niveau du cytoplasme c'est-à-dire sur l'état métabolique de ces cellules (phase de dégénérescences, par exemple). Les fixations de microscopie électronique le permettent et là aussi une abondante bibliographie descriptive (Von Wettstein, 1977) est disponible. 

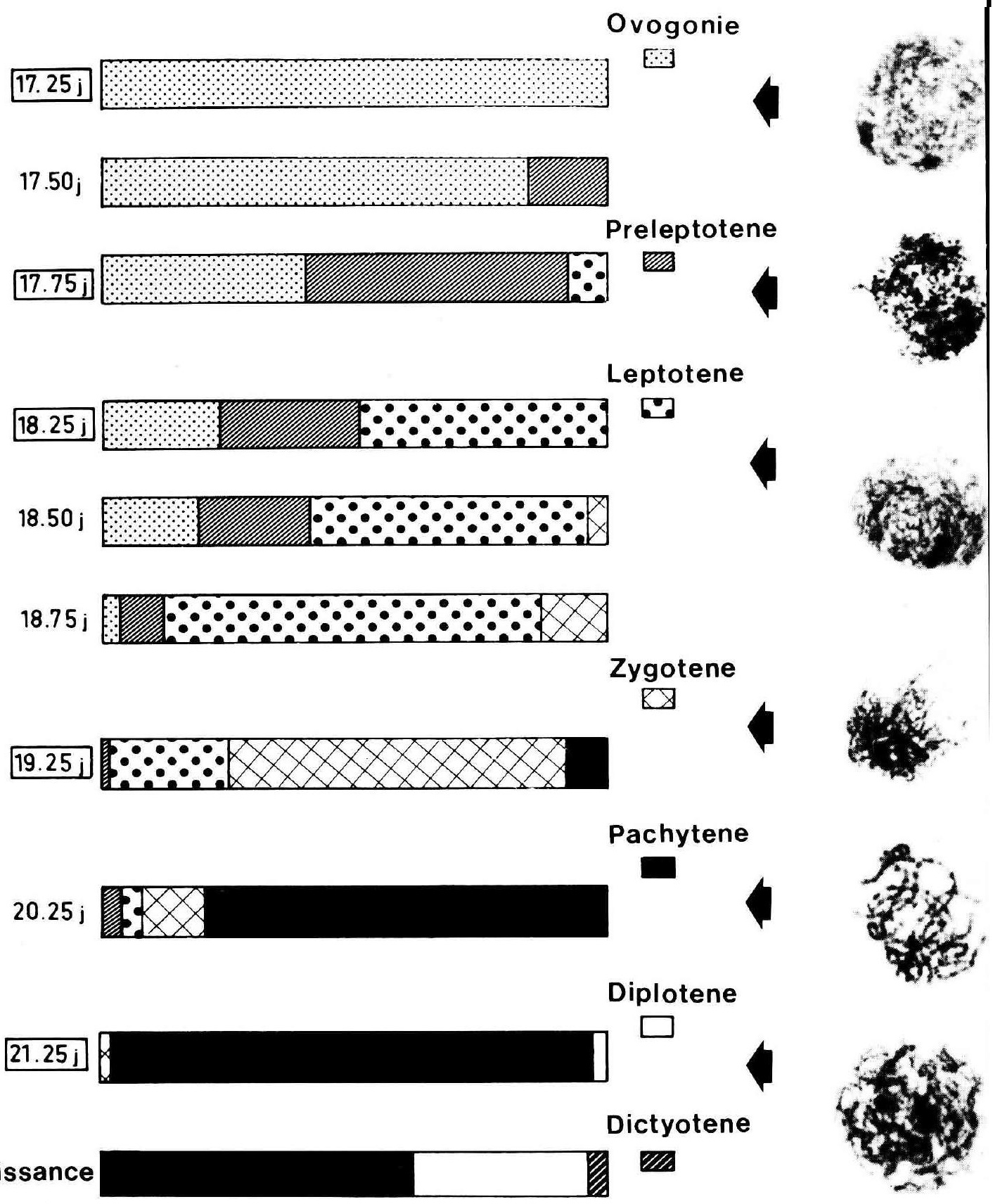

PLANCHE 1. - Diagramme d'évolution des stades méiotiques de cellules germinales de Rat au cours de leur développement. 
La technique des coupes semi-fines informe sur les relations cellules somatiques - cellules germinales ainsi qu'au niveau cytoplasmique et membranaire. Les images des cellules au cours de la méiose obtenues par cette technique sont rares. Afin d'y remédier, nous avons :

- comparé les images nucléaires trouvées sur coupes semi-fines à celles données par la cytologie nucléaire et définissant les stades de la prophase méiotique considérées comme étalon ;

- précisé les observations cytoplasmiques trouvées comme nouveaux critères de définition des stades par rapport à des observations en microscopie électronique (Bézard et Mauléon, 1984) ;

- rapproché les images histologiques courantes de ces descriptions sur coupes semi-fines pour apprécier la validité des expérimentations entreprises précédemment sur l'induction de la méiose.

La méthodologie proposée vise donc à présenter une étude comparative de diverses techniques sur ce matériel biologique.

\section{Matériel et méthodes.}

1. Animaux. - Des rats femelles Wistar de la souche 03-INRA, spécialement sélectionnés sur leur sensibilité à FSH et sur leur moindre variabilité de réponse aux hormones, ont aussi une moindre variabilité individuelle de structure ovarienne (Mauléon, 1978). Ces femelles ont été placées avec des rats mâles

\section{TABLEAU 1}

Evolution du pourcentage de cellules germinales aux différents stades nucléaires après étalement cytologique d'un ensemble de 8 ovaires.

\begin{tabular}{|c|c|c|c|c|c|c|c|c|c|}
\hline \multirow[b]{2}{*}{$\begin{array}{l}\text { Age des embryons } \\
\text { et nouveau-nés } \\
\text { (J p.c. et J p.n.) }\end{array}$} & \multicolumn{9}{|c|}{ Stades nucléaires } \\
\hline & G & $P L$ & $\mathrm{~L}$ & Z & $P$ & $\mathrm{D}$ & $\mathrm{DC}$ & $\begin{array}{l}\mathrm{Nb} \text { de } \\
\text { stades } \\
\text { nucléaires }\end{array}$ & $\begin{array}{l}\mathrm{Nb} \text { de } \\
\text { noyaux } \\
\text { comptés }\end{array}$ \\
\hline 17,25 & 100 & & & & & & & 1 & 71 \\
\hline 17,50 & 84 & 16 & & & & & & 2 & 145 \\
\hline 17,75 & 40 & 52 & 8 & & & & & 3 & 242 \\
\hline 18,25 & 24 & 28 & 48 & & & & & 3 & 212 \\
\hline 18,50 & 19 & 22 & $55\left(^{*}\right)$ & 4 & & & & 4 & 196 \\
\hline 18,75 & 3 & 9 & 75 & 13 & & & & 4 & 323 \\
\hline 19,25 & 0 & 1 & 24 & 67 & 8 & & & 4 & 207 \\
\hline 20,25 & 0 & 4 & 4 & 13 & 79 & & & 4 & 60 \\
\hline 21,25 & 0 & 0 & 0,5 & 1 & 96 & 2 & & 4 & 65 \\
\hline Naissance & 0 & 0 & 0 & 0 & 59 & 38 & 3 & 3 & 329 \\
\hline J1 & 0 & 0 & 0 & 0 & 41 & 38 & 21 & 3 & 99 \\
\hline
\end{tabular}

$\mathrm{G}$ : ovogonies ; PL : préleptotène ; $\mathrm{L}$ : leptotène ; $\mathrm{Z}$ : zygotène ; $\mathrm{P}$ : pachytène ; $\mathrm{D}$ : diplotène et Dc : dictyotène.

$\left({ }^{*}\right)$ Stade " dominant 》 leptotène mais avec 4 stades nucléaires différents aussi notre sélection a été 18,25 j p.c. avec 3 stades. Pourcentage d'un stade " dominant " correspondant à l'âge de prélèvement choisi. 
fertiles le soir du procestrus. Les femelles dont le frottis vaginal du matin suivant révèle la présence de spermatozoïdes, sont présumées gestantes et se trouvent à 0,25 jour post-coïtum à $9 \mathrm{~h}$ du matin.

2. Ages choisis pour les prélèvements. - C'est à partir d'une étude cytologique d'un ensemble de 8 ovaires de ratte, d'âge compris entre 17,25 jours post-cö̈tum (p.c.) et 0 jour post-natal (p.n.) (Bézard et Mauléon, 1981 ; PI. 1) qu'ont été choisies les meilleures périodes de prélèvement pour les autres études morphologiques. Ces périodes tiennent compte du moment où le nombre de types nucléaires différents est minimal et du moment où le pourcentage d'un stade " dominant » est maximal (tabl. 1).

Pour chaque âge de prélèvement ont été étudiées ;

- sur le même embryon, la morphologie des cellules germinales par techniques cytologiques de l'ovaire droit et histologique (coupes semi-fines) de l'ovaire gauche ;

- sur le même embryon, mais différent du précédent, la comparaison entre morphologie des cellules germinales, après histologie sur coupes semi-fines de I'ovaire droit et morphologie après histologie classique (coupes paraffine) de l'ovaire gauche.

3. Technique cytologique (Luciani et al., 1971). - Les phases importantes sont :

- prélèvement de l'ovaire fœtal placé dans une solution hypotonique de chlorure de potassium $(0,42 \%)$ pendant $15 \mathrm{~min}$ à la température ambiante ;

- fixation dans un mélange, préparé extemporanément, d'éthanol absolu et d'acide acétique glacial (3V: 1V) pendant $30 \mathrm{~min}$;

- dissection sous loupe binoculaire pour séparer tissu ovarien du tissu voisin et transfert dans de petits tubes coniques siliconés contenant le fixateur fraîchement préparé ;

- dissociation mécanique du tissu avec pipette fine siliconée par aspiration et refoulement ;

- centrifugation à 800 tours/min pendant $8 \mathrm{~min}$;

- reprise du culot par quelques gouttes d'acide acétique (45\%), agitation douce avec pipette fine bouchée et addition d'une goutte de méthanol absolu provoquant une turbulence des cellules d'où meilleure dispersion ;

- dépôt d'une goutte de suspension sur lame glacée humide puis passage à la flamme après étalement maximum ;

- coloration au Giemsa.

PLANCHE 2. - Séquence d'évolution de la cellule germinale de rat femelle après techniques microscopiques sur coupes semi-fines $(a, \times 1900)$ et cytologique $(b, \times 1700)$.

FIG. 1. - Ovogonie à 17,25 j d'âge post-coïtum ( $N u$ : Nucléole).

FIG. 2. - Préleptotène à 17,75 j d'âge post-coïtum.

FIG. 3. - Leptotène à $18,25 \mathrm{j}$ d'âge post-coïtum. 

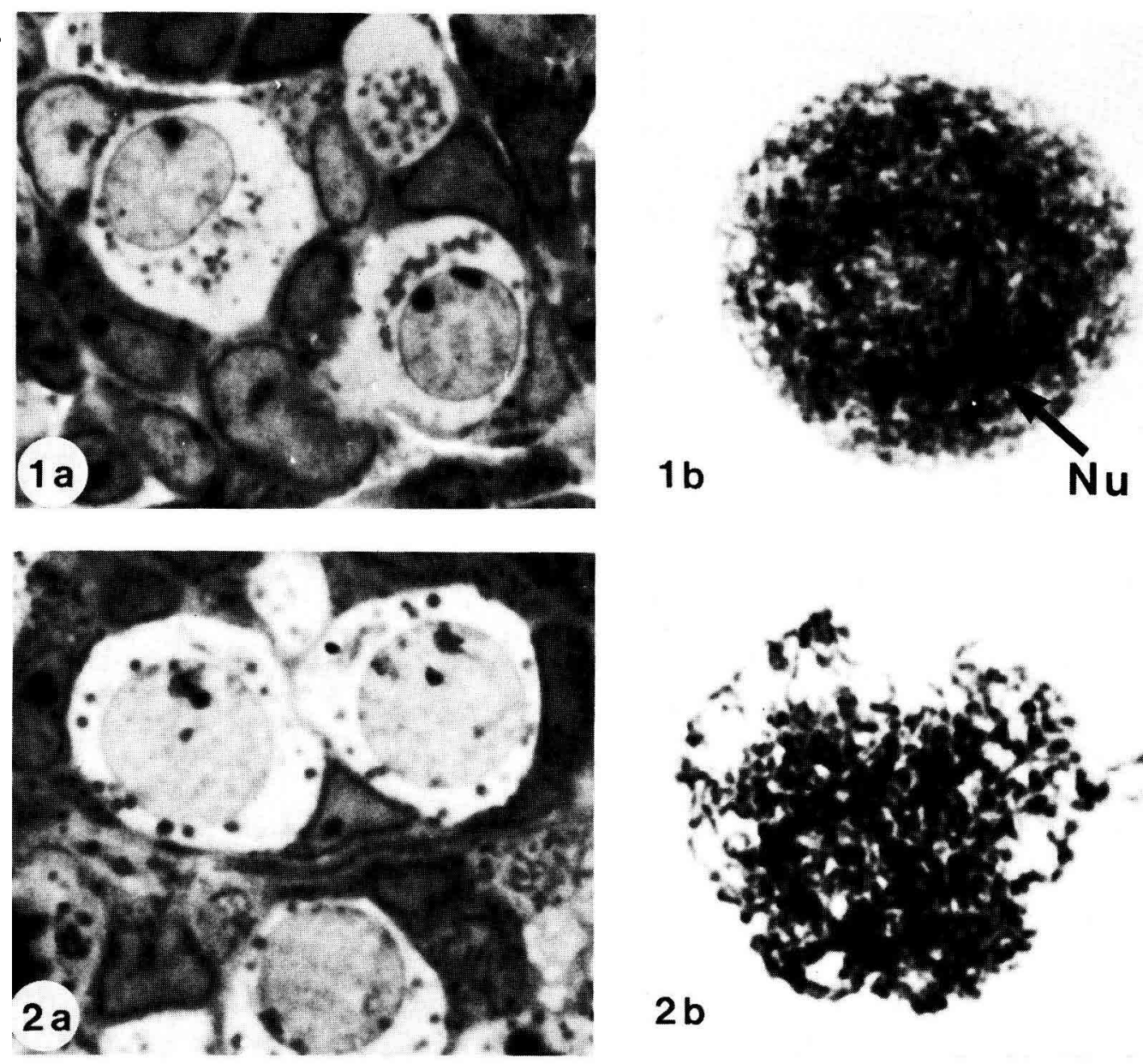
6 .

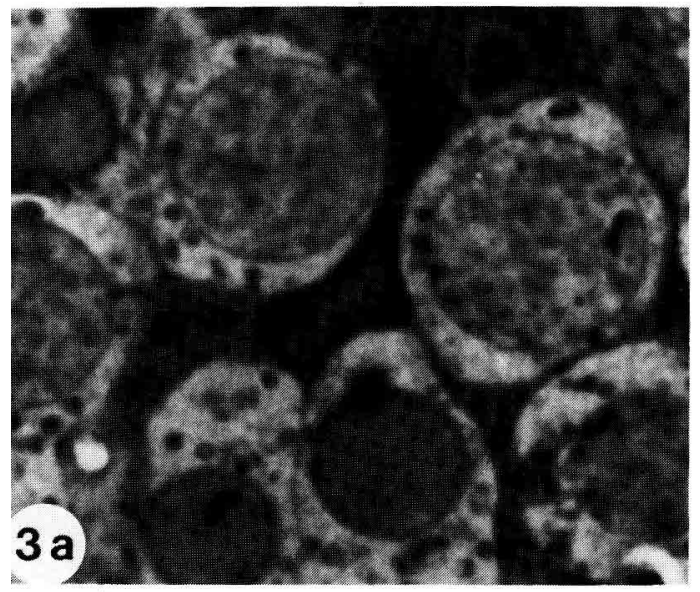

$2 b$

$x^{2}: \cdots, 190$ ' ixt $x^{2}+x^{\circ}+5$

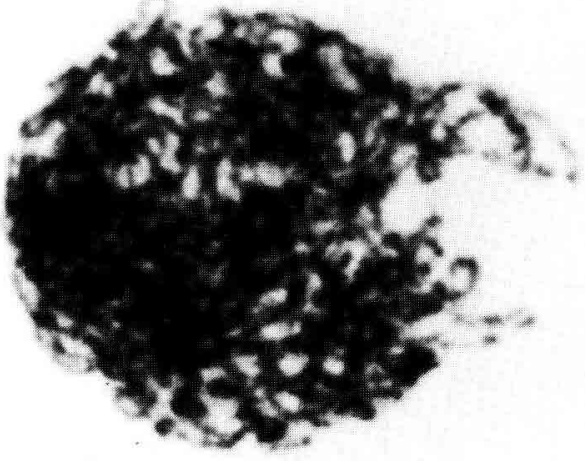

$3 b$ 


\section{Technique histologique sur coupes semi-fines}

- fixation au glutaraldéhyde $(2,5 \%$ dans cacodylate de sodium $0,1 \mathrm{M} ; \mathrm{pH} 7,3)$ à $4{ }^{\circ} \mathrm{C}$ pendant $1 \mathrm{~h}$;

- rinçage dans tampon cacodylate $(0,1 \mathrm{M})$;

- post-fixation dans acide osmique $(1 \%)$ à $0{ }^{\circ} \mathrm{C}$ pendant $1 \mathrm{~h}$;

- déshydratation et inclusion dans Epon 812 ;

- coupes de 0,5 à $1 \mu$ réalisées avec l'ultramicrotome Reichert ;

- coloration par flottaison par le bleu de Toluidine $10,5 \%$ dans tampon borate de sodium $4 \%$ ) chauffé jusqu'à apparition de vapeurs ;

- rinçage à l'eau distillée et différenciation à l'alcool éthylique absolu suivie d'un nouveau rinçage à l'eau ;

- montage en série sur lame et séchage à chaud.

Des coupes ultra-fines ont également été réalisées pour une étude ultérieure en microscopie électronique. Ces coupes ont été repérées par rapport aux coupes semi-fines.

\section{Technique histologique sur coupes incluses dans la paraffine}

- fixation au Bouin-Holland pendant 3 jours ;

- rinçage à l'eau distillée pendant $1 \mathrm{~h}$;

- déshydratation puis inclusion dans la paraffine;

- coupes de $5 \mu$ réalisées avec le microtome Reichert ;

- coloration nucléaire par la technique de Feulgen et Rossenbeck (1924).

\section{Résultats.}

I. Définition des stades de prophase méiotique en cytologie.

II n'existe pas d'étude longitudinale complète chez le rat donnant une description de la succession de ces stades. Celle que nous proposons a été établie en se référant aux études faites chez d'autres espèces (Homme : Kindred, 1963 ; Manotaya et Potter, 1963 ; Luciani et Stahl, 1971 ; Souris : Hartung et Stahl, 1977 ; Lapin : Devictor-Vuillet et al., 1973 ; Brebis : Mauléon et al., 1976).

1. Ovogonie. - La chromatine y est présente sous forme d'un très fin réseau de filaments peu dissociés et supportant de très petites masses d'hétérochromatine sur tout l'ensemble du noyau (PI. 2-1b). Les nucléoles sont souvent visibles.

2. Préleptotène. - Ce stade souvent peu ou mal décrit fait l'objet d'une planche complète (PI. 3).

PLANCHE 3. - Morphologie nucléaire de cellules germinales de ratte en préleptotène aux différents stades de condensation et de décondensation chromosomique $(\times 1700)$.

FIG. 1. - Début de condensation des chromosomes.

FIG. 2. - Condensation des masses chromatiniennes progressant le long des filaments mieux visibles.

FIG. 3. - Condensation devenant maximale, filaments chromosomiques très courts.

FIG. 4. - Décondensation laissant apparaître les filaments chromosomiques plus allongés avec des épaississements qui correspondent aux centromères.

FIG. 5. - Cellule germinale en métaphase de mitose normale.

FIG. 6. - Cellule germinale de mitose dite "atrétique». 

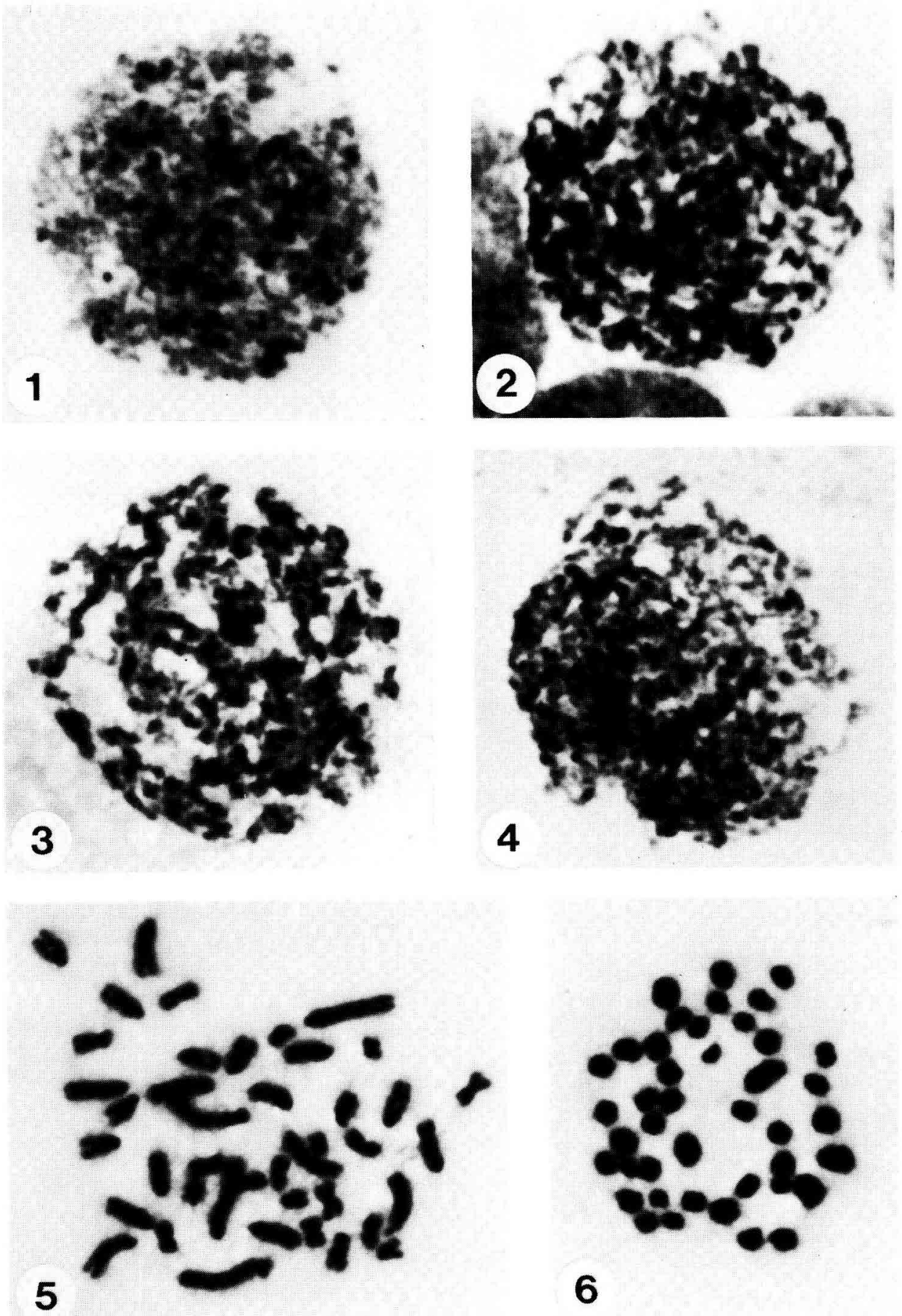
Lors du passage des noyaux de gonie au stade préleptotène, les filaments deviennent plus épais et les masses hétérochromatiniennes plus volumineuses et plus denses. L'ensemble nucléaire est très diffus et il est presque impossible, chez le rat, de déterminer avec précision le nombre de ces amas chromatiniens qui correspondraient aux chromocentres, selon ce qui a été trouvé chez la Souris (Hartung et Stahl, 1977) ou chez la Brebis (Luciani et al., 1979). Ces stades montrent un début de condensation des chromosomes (PI. 3-1).

Au cours de l'évolution du stade préleptotène, la condensation des masses chromatiniennes se précise et progresse le long des filaments chromosomiques, qui deviennent de plus en plus visibles (PI. 3-2).

La condensation des masses d'aspect hétéropycnotique devient présente sur toute la longueur des chromosomes rendant ceux-ci épais et très irréguliers. Cette condensation devient maximale et les filaments chromosomiques sont alors très raccourcis (PI. 3-3).

Ces phases de condensation progressive des éléments chromosomiques correspondent à ce que Walters nomme " early, mid, late and full condensation " (1970, 1976).

La décondensation qui suit est caractérisée par la réapparition des filaments chromosomiques qui s'allongent et s'étirent, mais renferment encore des épaississements souvent localisés à une extrémité : ce sont les centromères chromosomiques (PI. 2-2b et 3-4).

3. Leptotène. - Au stade "leptotène ", les chromosomes sont des filaments décondensés, très longs, qui s'enchevêtrent les uns aux autres ( $\mathrm{PI}$. 2-3b). Ils deviennent de plus en plus fins sur toute leur longueur mais conservent quelques renflements perlés qui sont les chromomères déjà repérables en fin préleptotène. Ces fins chromosomes restent très proches et peuvent être liés entre eux ; une complète individualisation de chaque élément $n^{\prime}$ est pas visible.

4. Zygotène. - Le stade « zygotène " est celui de l'appariement des chromosomes homologues; une convergence des filaments vers un pôle du noyau rend I'image chromosomique des cellules excentrée (PI. 4-1b). Les chromosomes sont étroitement pelotonnés, réalisant une masse compacte d'où s'échappent des anses chromosomiques qui gagnent la périphérie du noyau. lis présentent à leurs extrémités l'aspect d'une fourche à deux dents terminées par un épaississement.

5. Pachytène. - Au stade " pachytène », les appariements des chromosomes homologues sont terminés, la convergence a cessé et les chromosomes deviennent plus courts et plus épais ( $\mathrm{Pl}$. 4-2b et $3 \mathrm{~b}$ ). II est possible de constater l'appariement parfait des homologues par la mise en évidence de chaînons plus ou moins foncés mis bout à bout. Les parties les plus foncées sont les chromomères.

PLANCHE 4. - Séquence d'évolution de la cellule germinale de rat femelle après techniques microscopiques sur coupes semi-fines $(a, \times 1900)$ et cytologique $(b, \times 1700)$.

FIG. 1. - Zygotène à 19,25 j d'âge post-coïtum.

FIG. 2. - Pachytène à 20,25 j d'âge post-coïtum.

FiG. 3. - Pachytène " avancé " à 21,25 j d'âge post-coïtum. 

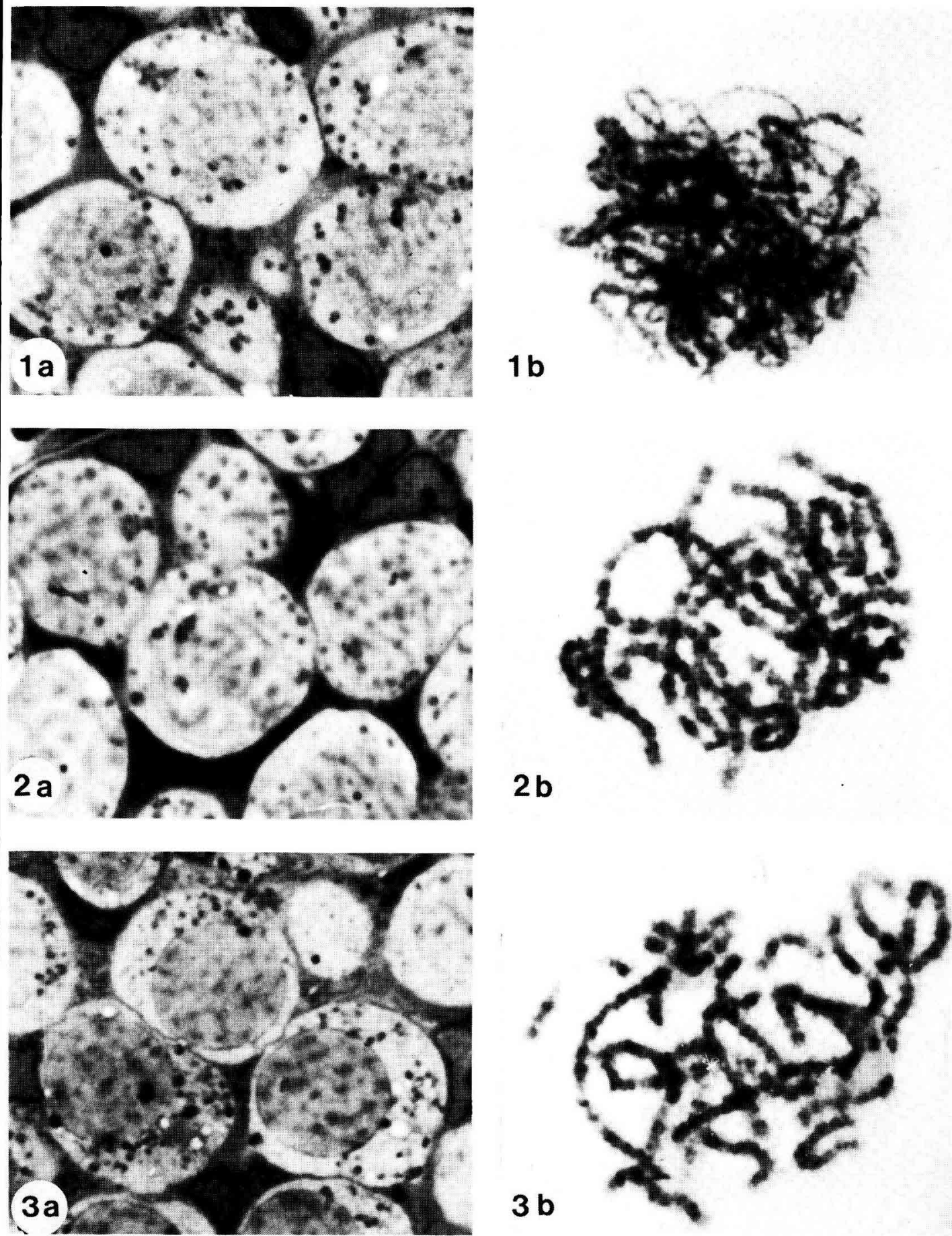
6. Diplotène. - A ce stade, les chromosomes homologues s'écartent en restant unis seulement au niveau des chiasmas (PI. 5-1b). C'est la déspiralisation intense des chromosomes; ils prennent l'aspect de filaments diffus, allongés et ténus. Les nucléoles sont à nouveau visibles.

7. Dictyotène. - C'est le stade de repos de l'ovocyte avec une augmentation considérable de la taille du noyau. Le matériel chromosomique est très diffus ; de nombreux micronucléoles sont présents en plus du volumineux nucléole (PI. 5-2b et 3b). Ce matériel nucléolaire abondant est en rapport avec l'intensité des synthèses protéiques qui caractérisent la croissance de l'ovocyte.

II. Comparaison des stades de prophase méiotique en microscopie sur coupes semi-fines et sur coupes paraffine avec référence aux stades précédents définis en cytologie.

1. Ovogonie. - Sur coupes semi-fines (PI. 6-1b et 1c), toutes les cellules germinales des ovaires de 17,25 j p.c. sont caractérisées par un large noyau sphérique fréquemment placé au centre de la cellule avec un ou le plus souvent deux gros nucléoles sphériques localisés au contact, ou à proximité de l'enveloppe nucléaire. La chromatine est dense et homogène. L'enveloppe nucléaire est épaisse et délimite de façon nette le contour du noyau. Le cytoplasme est clair avec des mitochondries souvent polarisées au niveau de l'appareil de Golgi. Les ovogonies sont parfois groupées par deux et il est possible de rencontrer deux noyaux dans un seul cytoplasme.

Sur coupes paraffine (PI. 6-1a), les ovogonies ne présentent qu'une structure chromatinienne dense et fortement colorée.

2. Préleptotène. - A 17,75 j p.c. (PI. 6 -2b et $2 \mathrm{c}$ ), les cellules germinales, sur coupes semi-fines, changent d'aspect dans leur majorité. En effet, la plupart d'entre elles $(40 \%)$ ont maintenant un noyau clair avec une chromatine ponctuée de petits amas denses. L'enveloppe nucléaire s'affine. Le nucléole devient rudimentaire et quelquefois fragmenté, sa localisation est le plus souvent proche de l'enveloppe nucléaire. Le large cytoplasme clair semble vide avec seulement quelques mitochondries éparses ou accolées à l'enveloppe nucléaire. Ce sont les "préleptotènes" en préparation à la méiose. A cet âge, des ovogonies sont encore présentes et d'autres sont en cours d'évolution vers le stade leptotène.

Sur coupes paraffine (PI. 6-2a), certains noyaux de cellules germinales deviennent plus clairs après coloration et présentent des amas de chromatine ; leurs contours sont peu définis. Ce sont peut-être les préleptotènes mais il est très difficile, voire impossible de faire une réelle différence avec les ovogonies.

PLANCHE 5. - Séquence d'évolution de la cellule germinale de rat femelle après techniques microscopiques sur coupes semi-fines $(1 \mathrm{a}, \times 1900 ; 2 \mathrm{a}$ et $3 \mathrm{a}, \times 1200)$ et cytologique $(\mathrm{b}, \times 1700)$.

FIG. 1. - Diplotène à la naissance.

FIG. 2. - Dictyotène à $1 \mathrm{j}$ après la naissance.

FIG. 3. - Dictyotène à $4 \mathrm{j}$ après la naissance. 
3. Leptotène. - Sur coupes semi-fines (PI. 6-3b et 3c), les cellules germinales possèdent en majorité des noyaux clairs et des enveloppes nucléaires très fines. Certaines ont une chromatine finement ponctuée, ce sont les quelques préleptotènes décrits précédemment ; d'autres $(48 \%)$ ont un contenu nucléaire qui présente de petits filaments chromosomiques individualisés : ce sont les « leptotènes ». La taille des noyaux augmente. Les rudiments nucléolaires sont devenus rares et filamenteux. Les mitochondries restent éparses dans un cytoplasme clair comme au stade préleptotène.

Les organelles cytoplasmiques ne sont pas visibles sur coupes paraffine (PI. 6-3a) ; seul le matériel nucléaire des leptotènes est représenté par un fin réseau de filaments s'entrecroisant sur toute la surface du noyau dont l'enveloppe n'est pas visible.

4. Zygotène. - Les coupes semi-fines (PI. 7-1b et 1c) permettent de visualiser l'enveloppe des noyaux "zygotènes » toujours très fine et donc peu visible. Les filaments chromosomiques sont plus longs et souvent placés par paires. Ils sont rangés parallèlement à partir d'un pôle du noyau proche de l'appareil de Golgi. Les rares nucléoles sont très petits. Les mitochondries peu nombreuses sont dispersées dans le cytoplasme. L'appareil de Golgi est maintenant très repérable grâce aux nombreux saccules dilatés. II est souvent localisé dans la région de polarisation des chromosomes.

Ce stade appelé " bouquet " sur coupes paraffine est identifié uniquement par un rassemblement des chromosomes à un pôle du noyau en un amas très dense fortement coloré et qui laisse échapper de fins filaments chromosomiques (PI. 7-1a).

5. Pachytène. - Sur coupes semi-fines (PI. 7-2b et $2 c, 3 b$ et $3 c$ ), c'est le stade nucléaire "dominant " avec des chromosomes bivalents épais bien individualisés. Ces chromosomes ont des contours francs pour $79 \%$ des cellules germinales en début de stade à 20,25 j p.c. (PI. $7-2 b$ et $2 c$ ) puis des contours plus diffus à 21,25 j p.c. (PI. 7-3b et 3c) lorsqu'ils sont plus évolués (96\%). Deux types de pachytènes sont différenciables avec cette technique d'histologie. Les enveloppes nucléaires encore très fines s'épaississent légèrement en fin de pachytène. Les rudiments nucléolaires augmentent de taille, d'aspect filamenteux à $20,25 \mathrm{j}$ p.c., ils deviennent sphériques à $21,25 \mathrm{j}$ p.c. Les mitochondries se polarisent autour de l'appareil de Golgi à saccules dilatés au stade " pachytène évolué " à 21,25 j p.c. alors qu'à 20,25 j p.c., elles sont dispersées dans tout le cytoplasme.

Sur coupes paraffine (PI. 7-2a et 3a), les filaments chromosomiques s'individualisent. Selon le plan de coupe, on les repère en position longitudinale (bâtonnets épais) ou transversale (petites sphères).

6. Diplotène. - Au stade "diplotène ", le noyau et le cytoplasme de I'ovocyte augmentent de taille. Sur coupes semi-fines (PI. 8-1b et $1 \mathrm{c}$ ), les filaments chromosomiques deviennent plus ténus. Ils sont de contours diffus et clairsemés dans le noyau. Les nucléoles redeviennent très volumineux. L'enveloppe nucléaire amorce un épaississement. La polarisation des mitochondries persiste autour d'un appareil de Golgi très développé avec de nombreuses vésicules. 

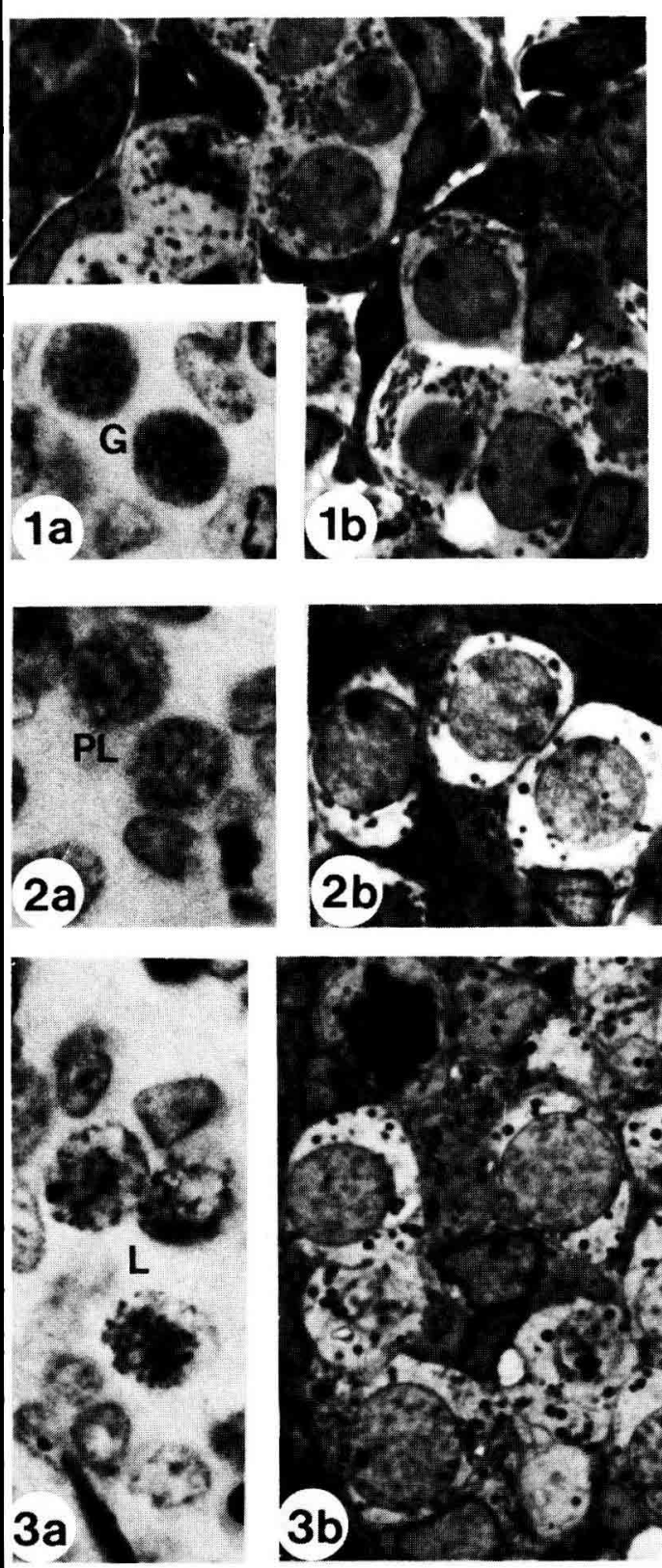
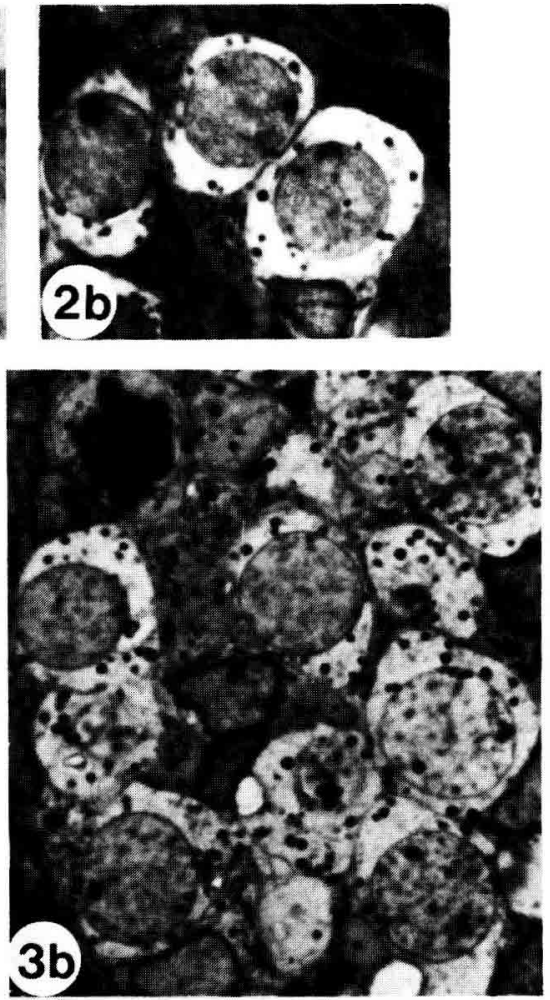

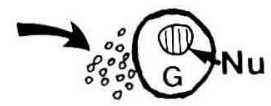

it $\mathbf{N}$

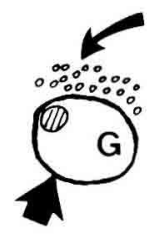

it
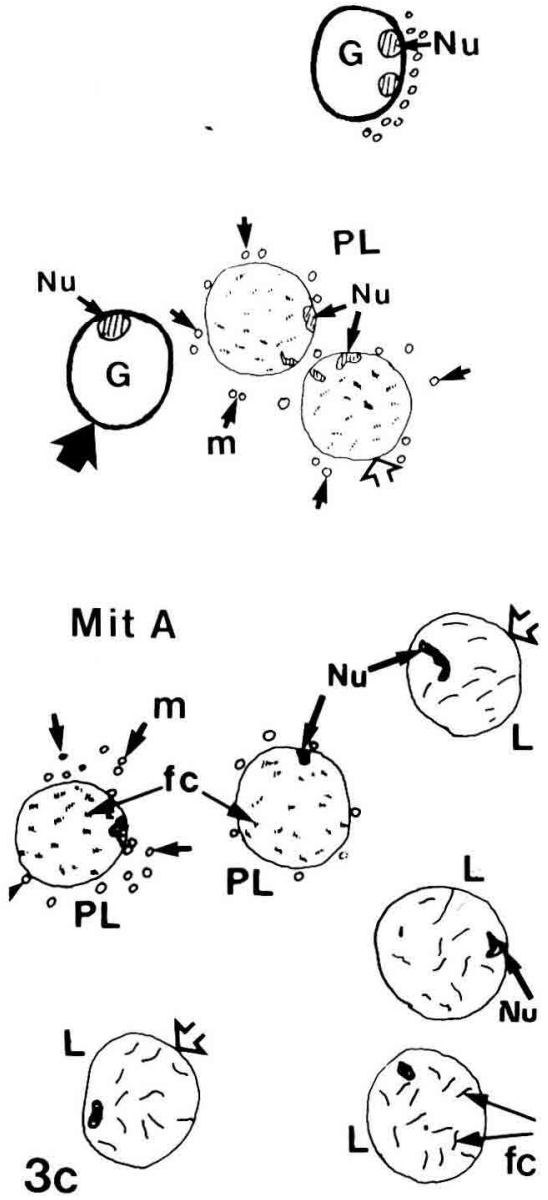

PLANCHE 6. - Séquence d'évolution des cellules germinales de rat femelle sur coupes paraffine (a) et semi-fines (b et c). X: 1400 .

FIG. 1. - Ovogonie à $17,25 \mathrm{j}$ d'âge post-coïtum.

FIG. 2. - Préleptotène à $17,75 \mathrm{j}$ d'âge post-coïtum.

FIG. 3. - Leptotène à $18,25 \mathrm{j}$ d'äge post-coitum.

$\mathrm{G}$ : ovogonie ; PL : Préleptotène ; $L$ : Leptotène ; Nu : Nucléole ; $m$ : mitochondrie ; fc : filament chromosomique; Mit $\mathrm{N}$ : mitose normale; Mit $\mathrm{A}$ : mitose atrétique; enveloppe nucléaire épaisse

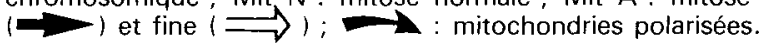


Sur coupes paraffine (PI. 8-1a), les noyaux diplotènes reprennent une forme sphérique, l'enveloppe nucléaire n'est pas visible, seul le matériel chromatinien se répartit dans l'ensemble du noyau et de fins filaments chromosomiques y sont encore visibles.

7. Dictyotène. - Les noyaux des ovocytes demeurent à ce stade de repos appelé « dictyotène » jusqu'à la puberté. Sur coupes semi-fines ( $\mathrm{PI}$. 8-2b et 2c), le contenu nucléaire est plus dense qu'au diplotène avec un nucléole sphérique. Quelques amas de chromatine s'accrochent à l'enveloppe nucléaire. Les mitochondries sont très nombreuses et redeviennent éparses dans un cytoplasme en pleine croissance.

L'évolution des cellules germinales en follicules primordiaux se fait progressivement. Chaque ovocyte s'individualise en s'entourant de cellules somatiques, cuboïdes ou allongées, claires ou foncées à l'intérieur d'une membrane basale. C'est la phase de "compartimentation » de l'ovaire décrite par Zamboni et al. (1979).

Sur coupes paraffine (PI. 8-2a), les ovocytes des follicules en formation trouvés à $1 \mathrm{j}$ p.n. montrent évidemment l'augmentation de taille. Les noyaux apparaissent clairs avec seulement un faible réseau de matériel plus dense.

La séquence d'évolution des stades méiotiques des cellules germinales présentée sur les planches 6,7 et 8 est établie avec plus de précision sur coupes semi-fines grâce à la visualisation des modifications des membranes et des éléments cytoplasmiques. Ces caractéristiques représentent de nouveaux critères (enveloppe nucléaire, nucléole, mitochondries) non repérables sur coupes paraffine où seule la structure nucléaire renseigne sur le stade de la cellule sans qu'il soit possible de différencier clairement les premiers stades du début de prophase méiotique.

\section{Discussion.}

Depuis les études anciennes sur l'ovogenèse des mammifères (Winiwarter, 1901 ; Winiwarter et Sainmont, 1909), suivies de travaux plus récents aux images microscopiques améliorées par la technique Feulgen, ce sont surtout des schémas d'évolution dans le temps qui ont été apportés chez les espèces peu étudiées auparavant (souris : Borum, 1961 ; McLaren et al., 1972 ; homme : Ohno et al., 1961 ; Blandau, 1969 ; lapin, brebis, vache et truie : Mauléon, 1961, 1966 ; rat :

PLANCHE 7. - Séquence d'évolution des cellules germinales de rat femelle sur coupes paraffine (a) et semi-fines (b et c). X: 1400 .

$$
\begin{aligned}
& \text { FIG. 1. - Zygotène à } 19,25 \text { j d'âge post-coïtum. } \\
& \text { FIG. 2. - Pachytène (début) à } 20,25 \mathrm{j} \text { d'âge post-coïtum. } \\
& \text { FIG. 3. - Pachytène (évolué) à } 21,25 \text { j d'âge post-coïtum. }
\end{aligned}
$$

L : Leptotène ; Z : Zygotène ; d Pachy : début Pachytène ; Pachy é : Pachytène évolué ; Nu : Nucléole ; * Go : appareil de Golgi ; fcp : filaments chromosomiques par paires ; $m$ : mitochondries; POLAR : Polarisation chromosomique. 

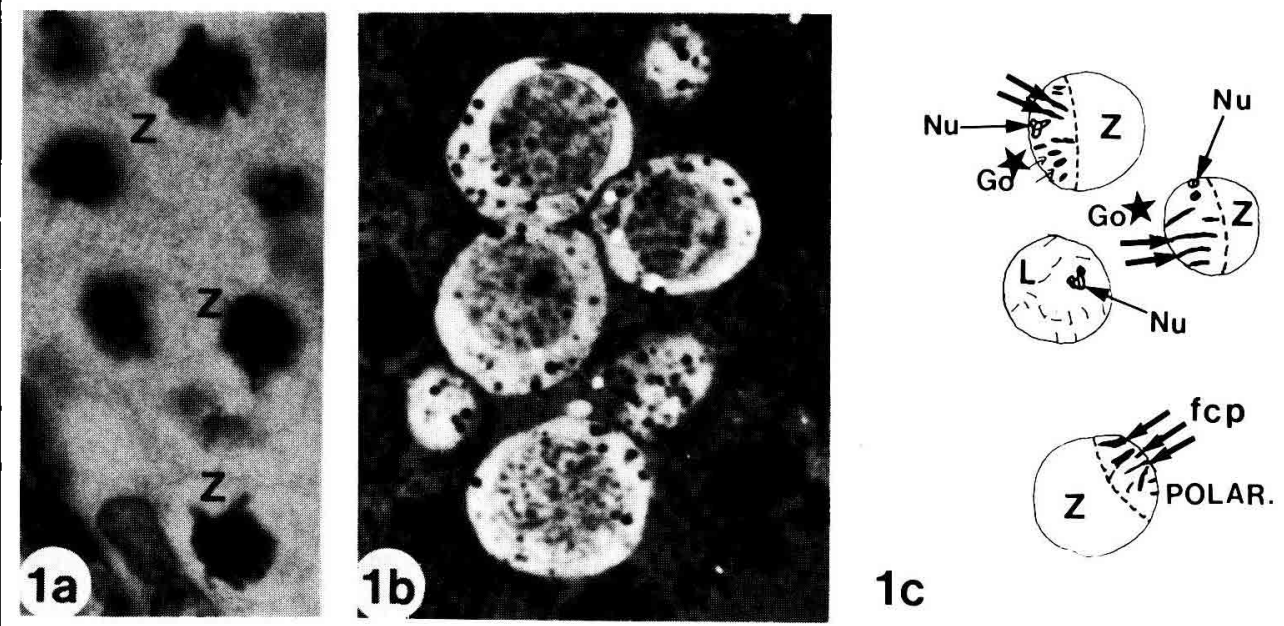

$1 c$
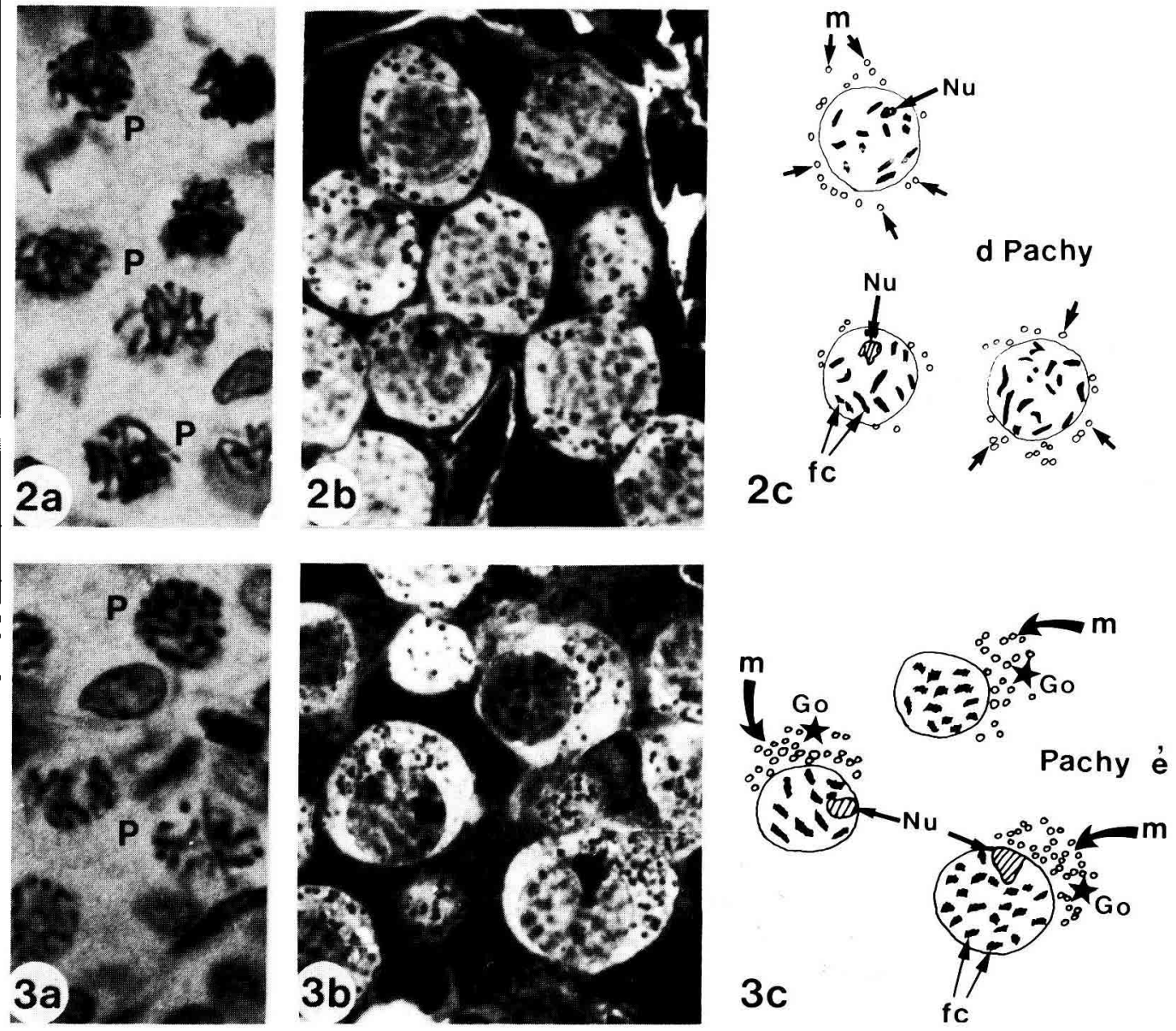

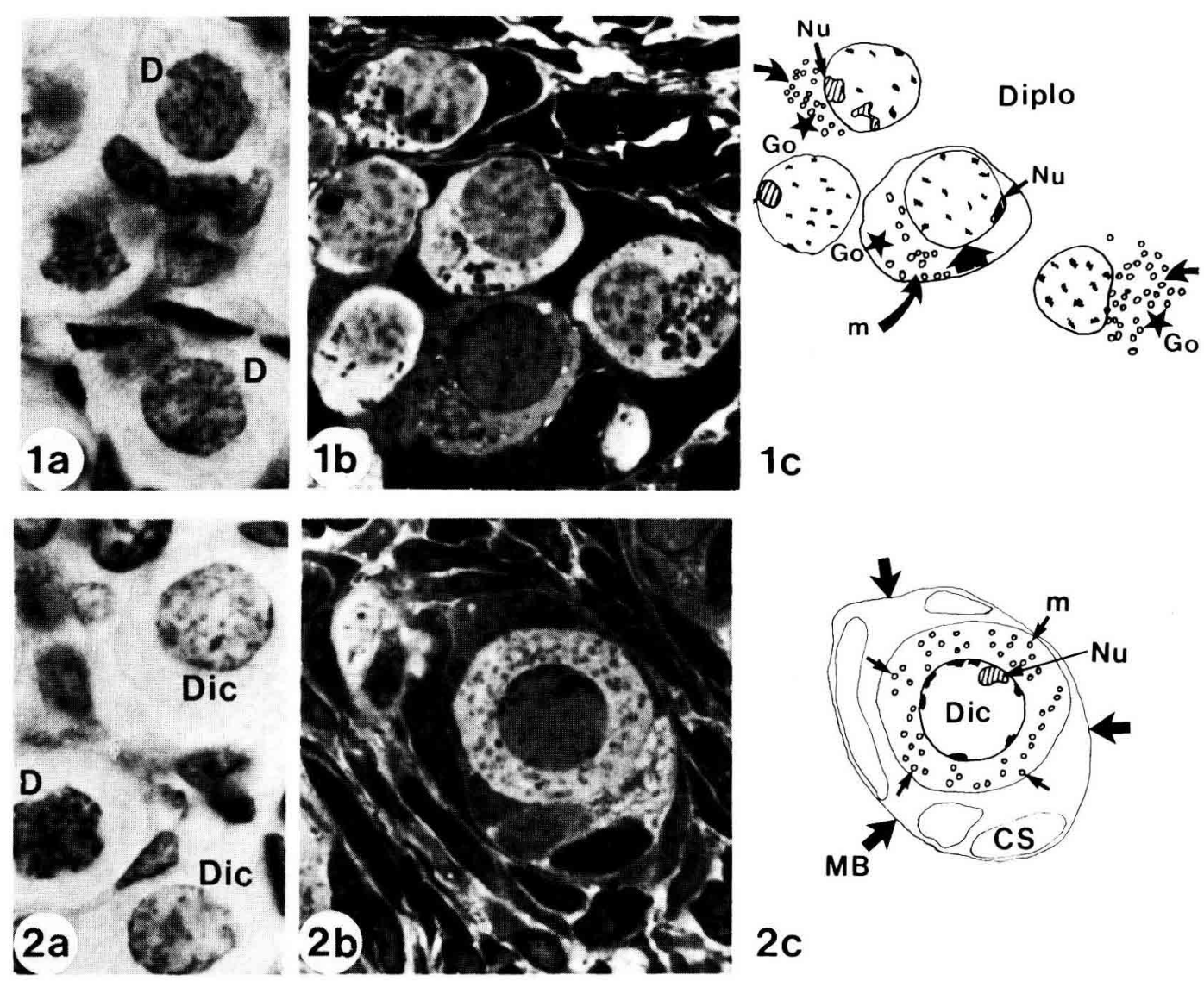

1c

PLANCHE 8. - Séquence d'évolution des cellules germinales de rat femelle sur coupes paraffine (a) et semi-fines (b et c). X: 1400.

FIG. 1. - Diplotène au jour de la naissance.

FIG. 2. - Dictyotène à $1 \mathrm{j}$ après la naissance.

Diplo: Diplotène ; Dic : Dictyotène ; Nu : Nucléole ; « Go : appareil de Golgi ; $\longrightarrow$ mitochondries polarisées; $\longrightarrow$ enveloppe nucléaire épaisse ; C.S. : Cellule Somatique : MB : Membrane Basale.

Beaumont et Mandl, 1962 ; Rivelis et al., 1976 ; lapin : Peters et al., 1965 ; hamster : Lemon et Morton, 1968 ; Challoner, 1974, 1975 ; Arrau et Roblero, 1979 ; porc : Black et Erickson, 1968 ; cheval : Deanesly, 1975).

Dans certaines études, aux images histologiques ont été ajoutées des images obtenues après "squashes " des cellules germinales chez le rat (Beaumont et Mandl, 1962), la souris (Borum, 1961) et I'homme (Ohno et al., 1962). La description des chromosomes eux-mêmes aux différents stades de la prophase méiotique a été faite chez l'homme par Kindred (1963), Manotaya et Potter (1963) et Luciani et Stahl (1971). La visualisation du nucléole et de ses rapports avec les 
chromosomes (Luciani et Stahl, 1971 ; Stahl et Luciani, 1972) puis les informations concernant les synthèses d'ARN (souris : Bakken et McClanahan, 1978 ; homme : Hartung et Stahl, 1978) et d'ADN (souris : Hartung et al., 1977 ; brebis : Luciani et al., 1979) ont tenté de définir en termes biochimiques la prophase méiotique.

Grâce à ces études des noyaux, la séquence d'évolution des stades nucléaires de cellules germinales de rat est clairement établie et la méthodologie utilisée ici en rapprochant une histologie sur coupes semi-fines a permis, à des stades précis de grande fréquence de certains états cytologiques, de trouver des critères morphologiques autres que nucléaires, caractéristiques de l'évolution des cellules germinales femelles durant l'ovogenèse. Même si l'évolution des chromosomes au cours de la prophase méiotique n'apparaît pas aussi clairement sur coupes semifines qu'en cytologie, principalement aux stades les plus précoces, préleptotène et leptotène, il existe des modifications au niveau de l'enveloppe nucléaire, du nucléole et des organelles cytoplasmiques portant sur leur forme, leur nombre et leur localisation qui sont autant de repères utiles à faible grandissement.

a) L'enveloppe nucléaire des cellules germinales qui disparaît au cours des multiplications ovoginales par mitoses est conservée durant la prophase méiotique. Ce phénomène a déjà été mis en évidence dès 1909 par Winiwarter et Sainmont, en histologie classique, puis souvent mis en doute. En histologie fine, on constate une variation morphologique de l'enveloppe nucléaire qui s'affine dès le début de la prophase méiotique pour s'épaissir de nouveau au stade diplotène.

Ces variations sont sans doute en relation avec la croissance de l'ovocyte c'est-à-dire l'augmentation du volume cytoplasmique de la cellule germinale. Selon sa structure, l'enveloppe nucléaire favorise ou gêne les échanges de matériaux entre noyau et cytoplasme, échanges nécessaires au cours de la croissance ovocytaire.

b) L'examen de coupes semi-fines révèle que le nucléole jusqu'alors volumineux se fragmente dès le préleptotène, c'est-à-dire avant que l'individualisation des chromosomes ne soit faite. II reprend sa forme sphérique au diplotène.

On a longtemps pensé que le nucléole disparaissait au cours de la prophase méiotique, car l'histologie classique ne permettait pas toujours de visualiser cette structure. Certains auteurs relataient son absence en fin de leptotène et sa présence au diplotène (porc : Black et Erickson, 1968 ; hamster : Challoner, 1974). En étude ultrastructurale, le nucléole est cependant décrit tout au long de la méiose (Franchi et Mandl, 1962 ; Schuchner, 1975 ; Stahl et al., 1978). L'évolution des composés nucléolaires est en relation avec les synthèses nucléaires. En effet, la fragmentation du nucléole correspondrait à l'arrêt des synthèses d'ARN qui reprennent dans le noyau en fin pachytène au moment où a lieu le regroupement des constituants nucléolaires (Mirre et Stahl, 1978).

c) Le matériel chromatinien passe d'une répartition homogène, durant les interphases, à une individualisation des chromosomes dès l'initiation méiotique. Si condensation et décondensation du contenu nucléaire, au stade préleptotène, sont facilement repérables avec les techniques cytologiques précédemment citées, sur coupes semi-fines ces modifications sont plus difficiles à remarquer. 
Cependant, dès le stade leptotène, les chromosomes homologues apparaissent comme des filaments courts et fins, très enchevêtrés mais encore peu visibles. Au stade zygotène, la figure de "bouquet ", décrite depuis longtemps en histologie classique (Winiwarter et Sainmont, 1909) et retrouvée en cytologie (Luciani et Stahl, 1971 ; Luciani et al., 1974), I'a été aussi sur coupes semi-fines (Bézard et Mauléon, 1981). De plus, la présence de l'appareil de Golgi au voisinage de cette polarisation chromosomique pose un problème non expliqué de relations entre les deux phénomènes. Au cours du stade pachytène, les masses chromosomiques deviennent si denses qu'elles sont facilement observables sur coupes semi-fines.

d) Le regroupement des mitochondries constaté dans le cytoplasme des ovogonies avant l'initiation méiotique est à rapprocher de la remarque déjà formulée par Franchi et Mandl (1962) d'une relation entre ce comportement et l'arrêt des multiplications mitotiques des cellules germinales. II a été trouvé également chez le mâle (Franchi et Mandl, 1964). Le nombre de mitochondries et leur déplacement dans le cytoplasme, tout au long de la prophase méiotique, doivent être liés au rôle physiologique important joué par ces organelles au cours des oxydations respiratoires, des échanges d'électrons, d'ions ou de molécules avec le hyaloplasme : ces phénomènes s'accentuent lors des synthèses des constituants mitochondriaux (Curgy, 1972).

En fin de pachytène et début diplotène, la polarisation importante entre appareil de Golgi et mitochondries est à rapprocher de la formation souvent décrite du " corps vitellin de Balbiani » qui, situé au niveau du complexe Golgien d'après ces descriptions, présente des structures très variables (Adams et Hertig, 1964 ; Hertig et Adams, 1967 ; Weakley, 1967, 1968 ; Zamboni, 1972). Ces phénomènes de polarisation des organelles dans les ovogonies âgées, peu avant le début de la prophase méiotique, puis leur dispersion dès l'entrée en méiose suivie d'une nouvelle polarisation avec l'appareil de Golgi en fin de pachytène sont des critères morphologiques faciles à repérer. Ces rassemblements de mitochondries correspondent peut-être aux regroupements décrits dans le spermatocyte de rat à cette même période d'évolution de la cellule germinale.

Il est noté, de 17,75 j p.c. à 19,25 j p.c. qu'un grand nombre de mitoses goniales présente une désorganisation des chromosomes qui deviennent des masses denses et sphériques plus ou moins dispersées dans la cellule (PI. 6-3b). Elles sont retrouvées dans l'étude cytologique (PI. 3-6). Ces mitoses, dites "atrétiques "), seraient dégénératives d'après Beaumont et Mandl (1962).

\section{Conclusion.}

Les observations en microscopie optique sur coupes semi-fines fournissent des repères faciles au cours de l'évolution des cellules germinales pendant la prophase méiotique.

En admettant une analogie de fréquence des figures observées en cytologie et sur coupes semi-fines, une séquence d'évolution des figures morphologiques des différents stades est proposée (fig. 1, 2, 3, 4, 5, 6, 7). 

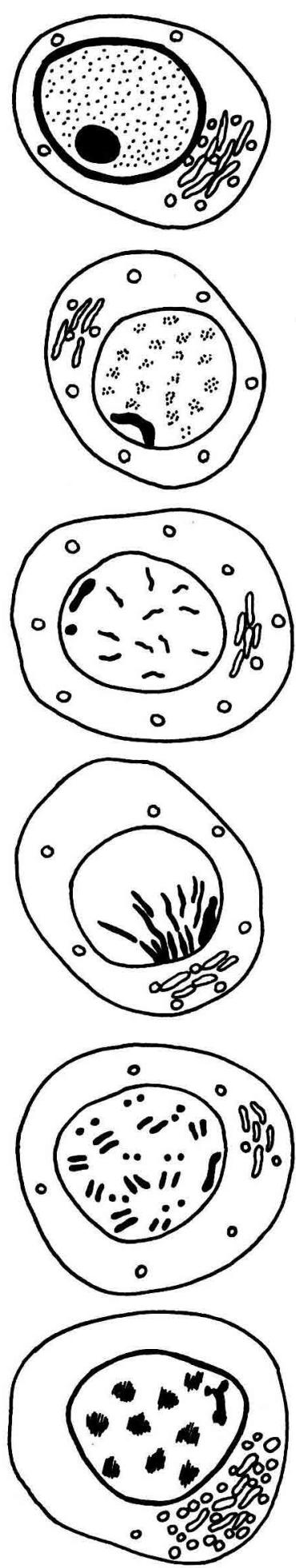

FIG. 1. - Ovogonie (PI. 6-1b et 1c) ;

- noyau à chromatine dense et homogène,

- 1 ou 2 gros nucléoles sphériques,

- membrane nucléaire épaisse,

- polarisation fréquente des mitochondries et de l'appareil de Golgi.

FIG. 2. - Préleptotène (PI. 6-2b et 2c) :

- noyau clair avec nombreux petits amas chromatiniens,

- disparition des gros nucléoles qui deviennent rudimentaires et fragmentés,

- perte de l'épaisse membrane nucléaire qui s'affine,

- mitochondries éparses dans le cytoplasme.

FIG. 3. - Leptotene (PI. 6-3b et 3c)

- noyau clair mais transformation des petits amas chromatiniens en batonnets ou filaments courts et fins,

- petits nucléoles rares, fins et allongés,

- membrane nucléaire très fine.

FIG. 4. - Zygotène (PI. 7-1b et 1c) ;

- noyau clair avec les filaments qui s'organisent par paires, s'allongent en position parallèle et se situent à un pôle dú noyau souvent du côté Golgi,

- petits nucléoles rares.

FIG. 5. - Pachytène (PI. 7-2b, 2c, 3b et 3c) ;

- ces filaments chromosomiques deviennent: très épais courts ou allongés selon le plan de coupe avec une répartition dans tout le nucléoplasme,

- disparition de la polarisation chromosomique,

- allongement des rudiments nucléolaires qui amorcent leur croissance.

- importante polarisation des mitochondries autour du Golgi à saccules dilatés en fin de stade pachytène. 


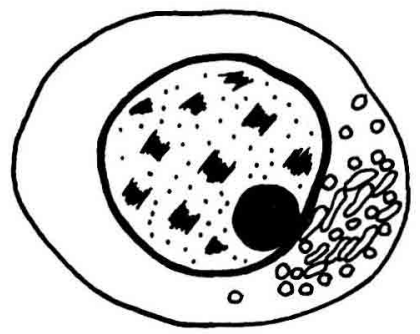

FIG. 6. - Diplotène (PI. 8-1b et 1c) ;

- large noyau avec nombreux petits amas chromosomiques très diffus,

- formation d'un nouveau nucléole volumineux et sphérique,

- début d'épaississement de la membrane nucléaire,

- large cytoplasme avec polarisation des mitochondries et Golgi vésiculeux,

- augmentation importante du volume du noyau et du cytoplasme.

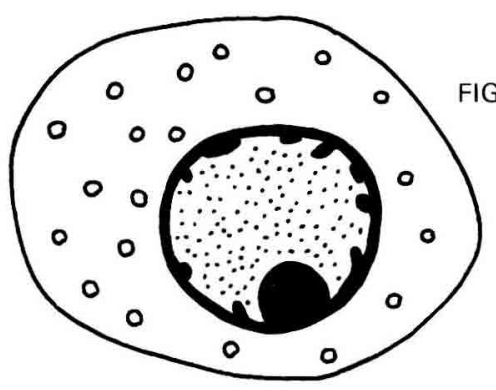

Reçu en mars 1984. Accepté en juin 1984.

\section{Références}

ADAMS E. C., HERTIG A. T., 1964. Studies on guinea pig oocytes. I. Electron microscopic observations on the development of cytoplasmic organelles in oocytes of primordial and primary follicles. J. Cell Biol., 21, 397-427.

ARRAU J., ROBLERO L., 1979. Méthode d'étude expérimentale de la prophase méiotique « in vivo » chez le hamster. Arch. Anat. microsc. Morphol. exp., 68, 73-84.

BAKKEN A. H., McCLANAHAN, 1978. Patterns of RNA synthesis in early meiotic prophase oocytes from fetal mouse ovaries. Chromosoma, 67, 21-40.

BEAUMONT H. M., MANDL A. M., 1962. A quantitative and cytological study of oogonia and oocytes in the foetal and neonatal rat. Proc. roy. Soc. Lond. B., 155, 557-579.

BÉZARD J., MAULÉON P., 1981. Ultrastructural changes in mammalian oocytes at the beginning of meiotic prophase with special reference to the nuclear pores studied by freeze fracture technique, 93-103. In A. G. BYSKOV, H. PETERS, Development and function of the reproductive organs. Exerpta med. Amsterdam, Oxford, Princeton.

BÉZARD J., MAULÉON P., 1984. Modifications ultrastructurales des cellules germinales femelles au cours de la prophase méiotique chez le rat: étude particulière des membranes après cryofracture. Reprod. Nutr. Dévelop., 24 (6) (sous presse).

BLACK J. L., ERICKSON B. H., 1968. Oogenesis and ovarian development in the prenatal pig. Anat. Rec., 161, 45-56.

BLANDAU R. J., 1969. Observations on living oogonia and oocytes from human embryonic and fetal ovaries. Amer. J. Obst. Gynec., 104, 310-319.

BORUM K., 1961. Oogenesis in the mouse. A study of the meiotic prophase. Exp. Cell Res., 24, 495-507.

CHALLONER S., 1974. Studies of oogenesis and follicular development in the golden hamster. 1. A quantitative study of meiotic prophase " in vivo ». J. Anat., 117, 373-383. 
CHALLONER S., 1975. Studies of oogenesis and follicular development in the golden hamster. 2. Initiation and control of meiosis " in vitro ». J. Anat., 119, 149-156.

CURGY J. J., 1972. Mitochondrial RNA synthesis during meiotic divisions in Locust male germ cells. Expt. Cell Res., 75, 127-137.

DEANESLY R., 1975. Germ cell development and the meiotic prophase in the fetal horse ovary. J. Reprod. Fert., suppl. 23, 547-552.

DEVICTOR-VUILLET M., LUCIANI J. M., STAHL A., 1973. Individualisation d'un stade préleptotène de condensation chromosomique dans l'ovocyte de la lapine. C. R. Acad. Sci. Paris, Sér. D, 276, 2453.

FEULGEN, ROSSENBECK, 1924. Ztschr. f. physiol. Chem., CXXXV, p. 202.

FRANCHI L: L., MANDL A. M., 1962. The ultrastructure of oogonia and oocytes in the foetal and neonatal rat. Proc. roy. Soc. Lond. B., 157, 99-114.

FRANCHY L. L., MANDL A. M., 1964. The ultrastructure of germ cells in foetal and neonatal male rats. J. Embryol. exp. Morph., 12, 289-308.

HARTUNG M., SOUCHIER C., STAHL A., 1977. Teneur en ADN de l'ovocyte de souris au stade préleptotène de condensation chromosomique. Ann. Biol. anim. Bioch. Biophys., 17, 9971004.

HARTUNG M., STAHL A., 1977. Preleptotene chromosome condensation in mouse oogenesis. Cytogenet. cell. Genet., 18, 309-319.

HARTUNG M., STAHL A., 1978. Autoradiographic study of RNA synthesis during meiotic prophase in the human oocyte. Cytogenet. cell. Genet., 20, 51-58.

HERTIG A. T., ADAMS E. C., 1967. Studies on the human oocyte and its follicle. I. Ultrastructural and histochemical observations on the primordial follicle stage. J. Cell Biol., 34, 647-675.

KINDRED J. E., 1963. Chromosomes of the ovary of the human fetus. Anat. Rec., 147, $295-311$.

LEMON J. G., MORTON W. R. M., 1968. Oogenesis in the golden Hamster (Mesocriatus auratus). A study of the first meiotic prophase. Cytogenetics, 7, 376-389.

LUCIANI J. M., BEZZARD J., DEVICTOR-VUILLET M., MAULÉON P., 1979. 3H-thymidine labelling pattern of preleptotene chromosome condensation stages in the foetal sheep ovary. Ann. Biol. anim. Bioch. Biophys., 19, 1241-1250.

LUCIANI J. M., DEVICTOR-VUILLET M., GAGNE R., STAHL A., 1974. An air drying method for first meiotic prophase preparations from mammalian ovaries. J. Reprod. Fert., 36, 409-411.

LUCIANI J. M., DEVICTOR-VUILLET M., STAHL A., 1971. Hypotonic Kcl. An improved method of processing human testicular tissue for meiotic chromosomes. Clin. Gen., 11, 32-36.

LUCIANI J. M., STAHL A., 1971. Etude des stades de début de la méiose chez l'ovocyte fœtal humain. Bull. Assoc. Anat., 56 ${ }^{\circ}$ Congrès, Nantes.

MANOTAYA T., POTTER E. L., 1963. Oocytes in prophase of meiosis from squash preparation of human fetal ovaries. Fertil. Steril., 14, 378-392.

MAULÉON P., 1961. Déroulement de l'ovogenèse comparé chez différents mammifères domestiques. Proc. IVth Cong. int. Reprod. anim., La Haye, 2, 167-174.

MAULÉON P., 1966. Cinétique de l'ovogenèse chez les mammifères. Arch. Anat. microsc. Morph. exp., 56, suppl. 3-4, 125-150.

MAULÉON P., 1978. Ovarian development in young mammals, 141-158. In D.B. Crighton, N.B. Haynes, G.R. Foxcroft, G.E. Lamming, Control of ovulation. Butterworths, London.

MAULÉON P., DEVICTOR-VUILLET M., LUCIANI J. M., 1976. The preleptotene chromosome condensation and decondensation in the ovary of the sheep embryo. Ann. Biol. anim. Bioch. Biophys., 16, 293-296.

McLAREN A., CHANDLEY A. C., KOFMAN-ALFARO S., 1972. A study of meiotic germ cells in the gonads of foetal mouse chimaeras. J. Embryol. exp. Morph., 27, 515-524.

MIRRE C., STAHL A., 1978. Ultrastructure and activity of the nucleolar organizer in the mouse oocyte during meiotic prophase. J. Cell Sci., 31, 79-100.

OHNO S., KLINGER H. P., ATKIN N. B., 1962. Human oogenesis. Cytogenetics, 1, $42-51$.

OHNO S., MAKINO S., KAPLAN W. D., KINOSITA R., 1961. Female germ cells of man. Exp. Cell Res., 24, 106-110.

PETERS H., LEVY E., CRONE M., 1965. Oogenesis in rabbits. J. exp. Zool., 158, 169-179.

RIVELIS C., PREPIN J., VIGIER B., JOST A., 1976. Prophase méiotique dans les cellules germi- 
nales de l'ébauche ovarienne de rat cultivée " in vitro " en milieu anhormonal. C. $R$. Acad. Sci. Paris, Sér. D, 282, 1429-1432.

SCHUCHNER E. B., 1975. Ultrastructural evolution of nucleoli of female rat germ cells. Fertil. Steril., 26, 924-931.

STAHL A., LUCIANI J. M., 1972. Nucleoli and chromosomes : their relationships during the meiotic prophase of the human fetal oocyte. Humangenetik, 14, 269-284.

STAHL A., MIRRE C., HARTUNG M., KNIBIEHLER B., NAVARRO A., 1978. Localisation and structure of nucleolar organizers in the oocyte during meiotic prophase I. Ann. Biol. anim. Bioch. Biophys., 18, 399-408.

WETTSTEIN (von) D., 1977. The assembly of the synaptinemal complex. Phil. Trans. roy. Soc. Lond. B., 277, 235-243.

WALTERS M. S., 1970. Evidence on the time of chromosome pairing from the preleptotene spiral stage in Lilium longiflorum " croft ". Chromosoma (Berl), 29, 375-418.

WALTERS M. S., 1976. Variation in preleptoten chromosome contraction among three cultivars of Lilium Iongiflorum. Chromosoma, 57, 51-80.

WEAKLEY B., 1967. Light and electron microscopy of developing germ cells and follicle cells in the ovary of the golden hamster : twenty-four hours before birth to eight days post-partum. $J$. Anat., 101, 435-459.

WEAKLEY B., 1968. Comparison of cytoplasmic lamellae and membranous elements in the oocytes of five mammalian species. Z. Zellforsch. Mikrosk. Anat., 85, 109-123.

WINIWARTER (von) H., 1901. Recherche sur l'ovogenèse et l'organogenèse de l'ovaire. Arch. Biol., 17, 33-201.

WINIWARTER (von) H., SAINMONT G., 1909. Nouvelles recherches sur l'ovogenèse et l'organogenèse de l'ovaire de mammifère (chat). Arch. Biol., 24, 1-142.

ZAMBONI L., 1972. Comparative studies on the ultrastructure of mammalian oocytes, 5-45. In J. BIGGERS, A. W. SHUETZ, Oogenesis. Univ., Park Press, Butterworths, London.

ZAMBONI L., BÉZARD J., MAULEEON P., 1979. The role of the mesonephros in the development of the sheep fetal ovary. Ann. Biol. anim. Bioch. Biophys., 19, 1153-1178. 